\title{
Author Correction: Listening to the Patient Perspective: Psychiatric Inpatients' Attitudes Towards Physical Restraint
}

\author{
Yaniv Spinzy ${ }^{1,2} \cdot$ Saed Maree $^{1} \cdot$ Aviv Segev ${ }^{1,2}$. \\ Gadi Cohen-Rappaport ${ }^{2,3}$
}

\section{Author Correction: Psychiatr Q \\ https://doi.org/10.1007/s11126-018-9565-8}

The original version of this article unfortunately contained a mistake in the author group section. The correct name of the second author is "Saed Maree" and the third author is "Aviv Segev."

The original article has been corrected.

The online version of the original article can be found at https://doi.org/10.1007/s11126-018-9565-8

\section{Yaniv Spinzy}

yanivspin@gmail.com

1 Shalvata Mental Health Center, Hod Hasharon, Israel

2 Sackler Faculty of Medicine, Tel Aviv University, Tel Aviv, Israel

3 Beer Yaakov-Ness Ziona Mental Health Center, Beer Yaakov, Israel 